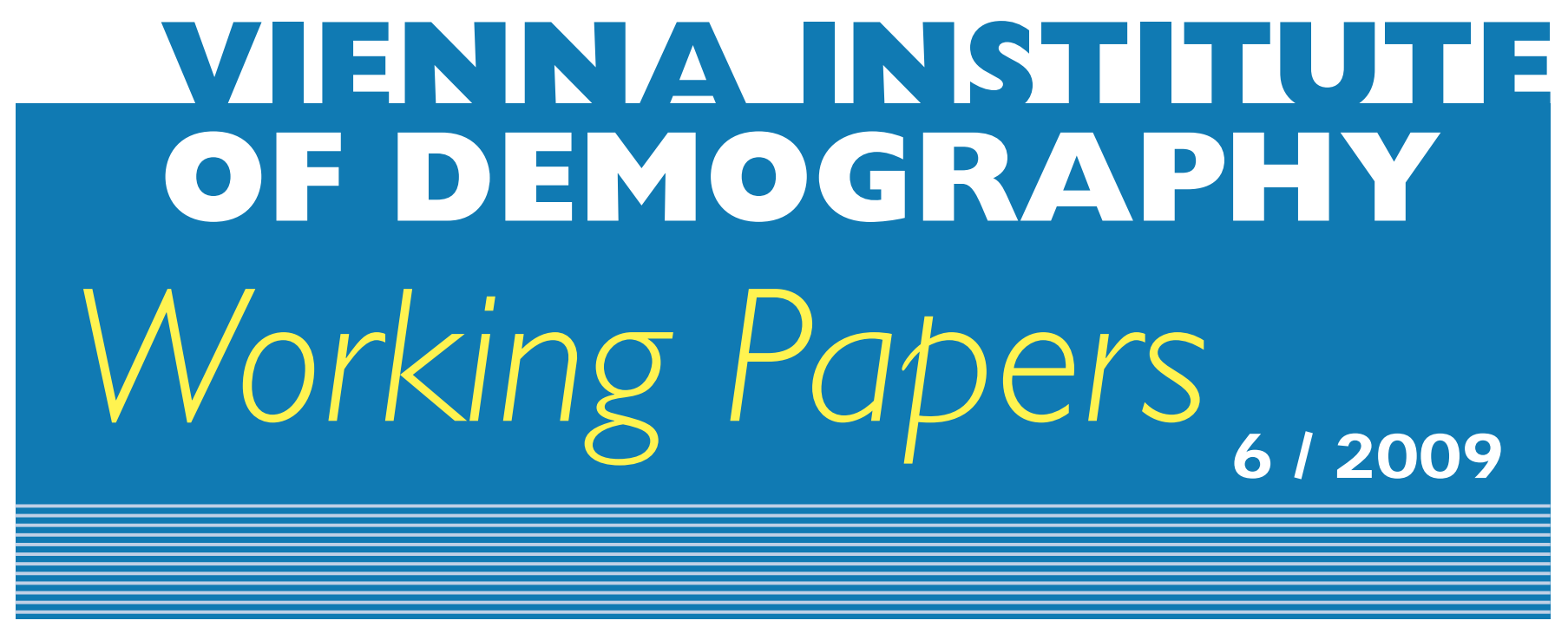

Klaus Prettner and Alexia Prskawetz

\title{
Decreasing Fertility, Economic Growth and the Intergenerational Wage Gap
}

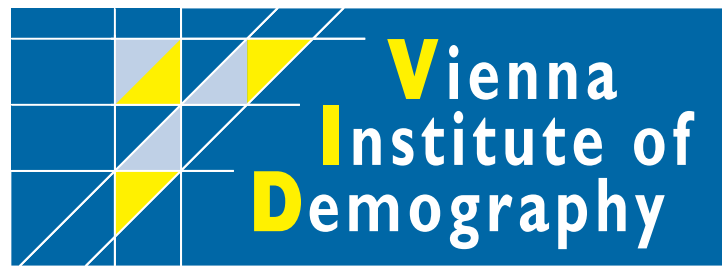

Vienna Institute of Demography Austrian Academy of Sciences

Wohllebengasse 12-14

A-I040 Vienna $\cdot$ Austria

E-Mail:vid@oeaw.ac.at

Website: www.oeaw.ac.at/vid

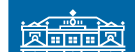

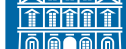

OAW Austrian Academy of Sciences 


\begin{abstract}
Persistent low fertility rates lead to lower population growth rates and eventually also to decreasing population sizes in most industrialized countries. There are fears that this demographic development is associated with declines in per capita GDP and possibly also increasing inequality of the wage distribution. We investigate whether this is true in the context of neoclassical growth models, augmented with endogenous fertility decisions and endogenous educational decisions. Furthermore we allow for imperfect substitutability across workers of different age in the production process and learning by doing effects as well as human capital depreciation. In particular, we assess the intergenerational wage redistribution effects which follow after a demographic change to persistent low fertility rates.
\end{abstract}

\title{
Keywords
}

Population decline, economic growth, intergenerational wage gap

\section{Authors}

Klaus Prettner, Vienna Institute of Demography, Austrian Academy of Sciences, and Austria and Institute of Mathematical Methods in Economics, Vienna University of Technology; Email: klaus.prettner@oeaw.ac.at

Alexia Prskawetz, Institute of Mathematical Methods in Economics, Vienna University of Technology, and Vienna Institute of Demography, Austrian Academy of Sciences; Email: afp@econ.tuwien.ac.at

\section{Acknowledgements}

We would like to thank Elise S. Brezis (Bar Ilan University), Michael Kuhn (Vienna Institute of Demography), Ronald Lee (University of California, Berkeley), Andrew Mason (University of Hawaii), Holger Strulik (University of Hannover), the participants of the "First Workshop on Dynamics, Optimal Growth and Population Change: Theory and Applications" in September 2008 in Milan/Italy and the participants of the Annual Meeting of the Austrian Economic Association in May 2009 in Linz/Austria for valuable comments and suggestions. Financial support by the Vienna Science and Technology Fund (WWTF) in its "Mathematics and..." call 2007 is greatly acknowledged. 


\title{
Decreasing Fertility, Economic Growth and the Intergenerational Wage Gap
}

\author{
Klaus Prettner and Alexia Prskawetz
}

\section{Introduction}

Fertility rates declined in most of the industrialized countries during the last decades (see for example Eurostat (2004), United Nations (2007)). Consequently, population growth rates decreased and will eventually even turn negative. Two central questions on the economic implications emerge in this context: First of all, will this development lead to a decrease in per capita output and if so, are there policies that could counteract its undesired development? Secondly, what are the redistributional effects between different age groups that are associated with such a demographic change?

The theoretical literature dealing with the first question can be distinguished into four categories: Exogenous growth models (see for example Ramsey (1928) and Solow (1956)) predict an inverse relationship between population growth and per capita output levels, since capital intensities increase if the population size decreases. In contrast, endogenous growth models (see for example Romer (1990), Grossman and Helpman (1991) and Aghion and Howitt (1992)) which concentrate on modelling research intensities, point out that a decline in the population size leads to fewer resources devoted to research and therefore to lower per capita output growth even in the long run. Jones (1995) showed that these models were not supported by empirical evidence, and he paved the way for scale free semi-endogenous growth models (see also for example Kortum (1997) and Segerström (1999)), where population size does not matter for long-run economic growth but rather persistent changes in the population size are important. A positive population growth rate is associated with positive long-run per capita output growth, whereas a stagnation of the population size eventually leads to a stagnation of per capita GDP. Another model class, dealing 
with the interrelations of population growth and economic development are unified growth models (see for example Galor and Weil (2000) and Strulik and Weisdorf (2008)). In these models a very long time horizon is analysed. The argument is that initially, per capita output growth was triggered by the demographic transition, i.e. falling population growth rates which led to an escape from the Malthusian trap. Evidently, theoretical models are inconclusive about the relationship between demographic change and per capita output growth, and the effects largely depend on the specific underlying assumptions.

To investigate the consequences of low fertility - in particular the effects of population ageing as resulting from persistent low fertility - on economic growth we start with a model of endogenous fertility and endogenous investment in children's human capital. Similar to recent work by Lee and Mason (2008) and based on the qualityquantity tradeoff model by Becker and Tomes (1976), our model implies that lower fertility induces higher educational investments and hence, higher per capita output. In addition we take two effects into account: on the one hand, human capital depreciates over the life-cycle as people tend to forget things they once learned; on the other hand, on the job training may increase experience and therefore improve the skills of unexperienced young workers over time. We refer to the first effect as human capital depreciation and to the second effect as learning by doing. For the sake of tractability we rely on a model specification without technological change but the main results carry over to the case where technology evolves exogenously. This framework is an appropriate description of a small economy whose technological frontier is determined by the rest of the world.

Regarding the second question on redistributional effects between age groups caused by persistent low fertility, we refer to the vast literature that links cohort size and macroeconomic outcomes (e.g. Macunovich (2002) for an excellent review). In this paper we focus on changes of the age structure of the labour force and their implications for wages and age specific productivity (Welch (1979), Lam (1989)). In particular we assume that workers of different age are not perfect substitutes in the production process. Evidence from the management literature (see for example Guest and Shacklock (2005) and Skirbekk (2005)) indicates that young and mature workers do exhibit different attributes. For example, employers report that younger workers tend to have better physical strength and endurance, vision, hearing, cognitive processing, intellectual capital, and adaptability, while mature workers are perceived as having better people management skills, judgement that depends on experience, reliability/dependability, loyalty, and attendance. These differences suggest that assuming imperfect substitutability between workers of different age is 
desirable. Consequently, any change in the age structure of the workforce - as a consequence of demographic changes that induce changes in the labour supply - will affect the intergenerational wage distribution. Besides the direct impact of changes in the age structure, the intergenerational wage distribution will also be determined by the human capital level of young vs. mature workers as it might change over cohorts and ones life-cycle. The cohort effects are captured by the assumption that parents decide on the human capital level of their children in combination with their number. Obviously, any change in the quantity of children caused by low fertility will impact on the quality of children. To study the life-cycle changes of productivity, we investigate the role of depreciation vs. appreciation (e.g. through learning by doing) of human capital during the working life. As our results show, higher relative human capital levels of young workers vs. mature workers does not need to imply higher relative returns in terms of wages.

The paper is organized as follows: In section 2 we introduce our theoretical model and in section 3 we present the central analytic results. In section 4 , two economies are simulated for identical parameter values except the fixed costs of children. Consequently, the two countries will differ with respect to fertility rates and hence with respect to their demographic developments. The differences of these two economies with respect to per capita output as well as the implications of low fertility for the distribution of income between young and mature workers (across generations over time) are illustrated. Finally, in section 5 we draw conclusions and sketch out opportunities for policy-makers to intervene.

\section{Structure of the model}

The framework used to describe our economy is an overlapping generations version of a neoclassical growth model with endogenous fertility and endogenous educational decisions. The population consists of four cohorts, children, young workers, mature workers and retirees. Each phase in an individual's lifetime lasts for twenty years, such that people die at the age of eighty.

Children do not face a decision problem, they receive consumption goods and education from their parents. Parents are young workers who have to decide how to allocate their potential income between consumption and investment into offspring. Note, that they do not face a savings decision at this stage. Investment into offspring either takes the form of investments into the number of children or investments into their education. This reflects the well known quality-quantity tradeoff (see for example Willis (1974) and Becker and Tomes (1976)). In particular, the utility 
function of young workers is a generalized version of the utility function applied in Galor and Weil (2000), adapted such that it allows for a differentiation between young and mature workers. Mature workers face the dynamic decision problem of optimally allocating their income between current consumption and consumption in the next stage of their life-cycle when they are retirees and do not have labour income. Hence, by assuming that only mature workers save, we decompose the whole life-cycle optimization into two sub-problems: one for young workers and one for mature workers. While this assumption allows us to solve the model analytically, it is also justified by empirical observations: net savings of individuals tend to peak between the age of 40 to 59 (see for example Börsch-Suppan et al. (2008)).

The firm sector uses labour input of young and mature workers and capital to produce a final good, which can be considered as a consumption aggregate. Young workers and mature workers are imperfect substitutes in the production process, so we introduce a parameter that measures incomplete substitutability between these two groups of workers. Finally, we assume that markets are perfectly competitive, such that factors are paid their marginal products.

Subsection 2.1 formally describes the decision problem of young workers, subsection 2.2 refers to human capital depreciation and learning by doing effects, subsection 2.3 formally describes the decision problem of mature workers and subsection 2.4 refers to the production side of the economy.

\subsection{The decision problem of young workers}

The utility function of young workers is a generalized version of the one used by Galor and Weil (2000), where utility positively depends on own consumption, the number of children, and children's own potential income in the two periods when they supply their available time on the labour market. Therefore we have

$$
U_{t}^{t-1}=\left(c_{t}^{t-1}\right)^{1-\gamma}\left(w_{t+1}^{t} n^{t} h_{t+1}^{t}+w_{t+2}^{t} n^{t} h_{t+2}^{t}\right)^{\gamma},
$$

where subscripts refer to time and superscripts refer to the date of birth of the respective cohort. $U_{t}^{t-1}$ describes utility of young workers in period $t, c_{t}^{t-1}$ refers to consumption of young workers in period $t, n^{t}$ is the number of young worker's children, $w_{t+1}^{t} h_{t+1}^{t}$ the potential income of these children when they are young workers, $w_{t+2}^{t} h_{t+2}^{t}$ their potential income when they are mature workers, and $\gamma \in[0,1]$ represent the household's preferences for children. The budget constraint, where 
costs of children are foregone wages, has the following form:

$$
w_{t}^{t-1} h_{t}^{t-1} n^{t}\left(\tau^{f}+\tau^{v} e^{t}\right)+c_{t}^{t-1}=w_{t}^{t-1} h_{t}^{t-1} .
$$

In this setting $\tau^{f} \in[0,1]$ refers to the fixed costs of each child, whereas $\tau^{v} \in[0,1]$ represents its variable costs associated with one unit of education, $e^{t}$. The left hand side of equation (2) consists of total expenditures on consumption and children, whereas the right hand side refers to the potential income young workers are able to earn if they supply their whole available time on the labour market. Additionally, we implement the assumption that people born at $t-1$ do not educate themselves in period $t$. Human capital stock, net of depreciation and learning by doing effects, is therefore determined at the end of childhood for the whole remaining lifetime, i.e. $h_{t+1}^{t}\left(e^{t}\right)=h_{t+2}^{t}\left(e^{t}\right)$. Optimal consumption, fertility, and education can be obtained by maximizing utility in equation (1) subject to the budget constraint (2). Despite the introduction of an additional generation, as compared to Galor and Weil (2000), the results are similar:

$$
\begin{aligned}
c_{t}^{t-1} & =(1-\gamma) w_{t}^{t-1} h_{t}^{t-1} \\
n^{t} & =\frac{\gamma}{\tau^{f}+\tau^{v} e^{t}} \\
G\left(e^{t}\right) & \equiv\left(\tau^{f}+\tau^{v} e^{t}\right)\left(h_{t+1}^{t}\right)^{\prime}\left(e^{t}\right)-\tau^{v} h_{t+1}^{t}\left(e^{t}\right)=0 .
\end{aligned}
$$

Equation (3) follows from the specification of the Cobb-Douglas utility function and states that a fraction $1-\gamma$ of young worker's potential income in period $t$ is spent on consumption. Equation (4) describes the fact that optimal fertility increases with the preferences for children in young worker's utility, whereas it decreases with fixed and variable costs of these children. Finally, equation (5) is an implicit function for optimal education. Lee and Mason (2008) propose the following specific functional form for the dependence of human capital on education

$$
h_{t+1}^{t}\left(e^{t}\right)=\alpha\left(e^{t}\right)^{\beta},
$$

where $\alpha \geq 0$ and $\beta \geq 0$ are arbitrary parameter values and $\beta<1$ would ensure decreasing returns to scale in the production of human capital with respect to education. With this specific functional form, the following expression for optimal 
education can be derived

$$
e^{t}=\frac{\beta}{1-\beta} \frac{\tau^{f}}{\tau^{v}}
$$

It states that optimal education increases with fixed costs of children and with efficiency of education measured by the parameter $\beta$, whereas it decreases with the variable costs of education.

\subsection{Learning by doing}

Human capital, net of depreciation and learning by doing effects, is determined via education of children. After the end of childhood it remains the same during the rest of an individual's life. However, we generalize the model by introducing two additional effects: on the one hand we allow people to forget skills and abilities over time and refer to this as the human capital depreciation effect; on the other hand we take the possibility into account that young workers improve their skills during the working process and refer to this as the learning by doing effect. Human capital of mature workers can then be written as

$$
h_{t+1}^{t-1}=(1+\delta) h_{t}^{t-1}
$$

where $\delta \in[-1, \infty)$ is a measure for the relative size of the human capital depreciation rate and the learning by doing effect. In case that $\delta<0$, depreciation of abilities and skills outweighs the learning by doing effect, whereas it is the other way round if $\delta>0$.

\subsection{The decision problem of mature workers}

Mature worker's utility positively depends on consumption in the period when they supply their available time on the labour market as well as on discounted consumption from the period when they are retirees and do not earn any labour income (see Diamond (1965)). Therefore the function

$$
U_{t+1}^{t-1}=\left(c_{t+1}^{t-1}\right)^{1-\epsilon}+\frac{1}{\theta}\left(c_{t+2}^{t-1}\right)^{1-\epsilon}
$$

can be used as their utility function, where $\epsilon \in[0,1]$ determines the intertemporal elasticity of substitution, and $\frac{1}{\theta}$ is the discount factor determined by $\theta=1+\rho$, with $\rho \geq 0$ being the discount rate. The budget constraint

$$
c_{t+1}^{t-1}+\frac{c_{t+2}^{t-1}}{1+r_{t+1}}=w_{t+1}^{t-1}(1+\delta) h_{t}^{t-1}
$$


where $r_{t+1}$ is the interest rate between $t+1$ and $t+2$, states that remaining lifetime consumption of mature workers, i.e. consumption in period $t+1$ and discounted consumption in period $t+2$, must not exceed remaining lifetime wage income of mature workers. The solution for optimal consumption in both relevant periods yields:

$$
\begin{aligned}
c_{t+1}^{t-1} & =\frac{\theta^{\frac{1}{\epsilon}} w_{t+1}^{t-1}(1+\delta) h_{t}^{t-1}}{\theta^{\frac{1}{\epsilon}}+\left(1+r_{t+1}\right)^{\frac{1}{\epsilon}-1}} \\
c_{t+2}^{t-1} & =\frac{\left(1+r_{t+1}\right)^{\frac{1}{\epsilon}} w_{t+1}^{t-1}(1+\delta) h_{t}^{t-1}}{\theta^{\frac{1}{\epsilon}}+\left(1+r_{t+1}\right)^{\frac{1}{\epsilon}-1}} .
\end{aligned}
$$

Via the fact that $c_{t+1}^{t-1}=\left(1-s_{t+1}^{t-1}\right) w_{t+1}^{t-1}(1+\delta) h_{t}^{t-1}$, where $s_{t+1}^{t-1}$ denotes the savings rate of mature workers, this savings rate can be derived as:

$$
s_{t+1}^{t-1}=\frac{\left(1+r_{t+1}\right)^{\frac{1}{\epsilon}}}{\theta^{\frac{1}{\epsilon}}+\left(1+r_{t+1}\right)^{\frac{1}{\epsilon}-1}} .
$$

\subsection{The Production Side}

The production side of the economy can be described using a nested CES-production function that accounts for productivity differentials as well as for imperfect substitutability between young and mature workers (see for example Lam (1989)):

$$
Y_{t}=K_{t}^{\eta}\left[\left(\left(h_{t}^{t-1} N_{t}^{t-1}\right)^{\kappa}+\left(h_{t}^{t-2} N_{t}^{t-2}\right)^{\kappa}\right)^{\frac{1}{\kappa}}\right]^{1-\eta}
$$

In this specification $Y_{t}$ describes aggregate output, $K_{t}$ denotes the aggregate capital stock, $N_{t}^{t-1}$ is the young worker's cohort size, $N_{t}^{t-2}$ describes the mature worker's cohort size, $\eta \in[0,1]$ is the capital share of output and the parameter $\kappa \in(-\infty, 1]$ determines $\sigma$, the elasticity of substitution between members of the two cohorts as $\sigma=\frac{1}{1-\kappa}$. Note that for $\kappa=1$ there is perfect substitution between the two age groups and $\sigma$ tends towards $\infty$. Finally, the composites $h_{t}^{t-1} N_{t}^{t-1}$ and $h_{t}^{t-2} N_{t}^{t-2}$ can be referred to as the available efficiency units of young and mature workers, respectively ${ }^{1}$. Per capita GDP is equivalent to per capita production and therefore amounts to

$$
Y_{t}=\frac{K_{t}^{\eta}\left[\left(\left(h_{t}^{t-1} N_{t}^{t-1}\right)^{\kappa}+\left(h_{t}^{t-2} N_{t}^{t-2}\right)^{\kappa}\right)^{\frac{1}{\kappa}}\right]^{1-\eta}}{N_{t}^{t}+N_{t-1}^{t}+N_{t-2}^{t}+N_{t-3}^{t}} .
$$

Since there are competitive markets for the aggregate consumption good, productive factors are paid their marginal products. Thus the real wage rate of young workers,

\footnotetext{
${ }^{1}$ Note that we could in principle write $h_{t}^{t-2}=(1+\delta) h_{t-1}^{t-2}$.
} 
$w_{t}^{t-1}$, the real wage rate of mature workers, $w_{t}^{t-2}$, and the capital rental rate, $r_{t}$, are given by the derivatives of the production function with respect to the productive factor under consideration. This leads to the following expression for wages of young workers:

$$
w_{t}^{t-1}=\frac{K_{t}^{\eta}(1-\eta)\left(h_{t}^{t-1} N_{t}^{t-1}\right)^{\kappa-1} h_{t}^{t-1}}{\left(\left(h_{t}^{t-1} N_{t}^{t-1}\right)^{\kappa}+\left(h_{t}^{t-2} N_{t}^{t-2}\right)^{\kappa}\right)^{\frac{\kappa+\eta-1}{\kappa}}} .
$$

Equation (16) shows that these wages increase if the capital stock increases or the number of young workers decreases. The effects of increases in human capital of both types of labour and the effects of increases in the number of mature workers depend on the elasticity of substitution between age groups, i.e. on the value of $\kappa$. Wages of mature workers can be derived as:

$$
w_{t}^{t-2}=\frac{K_{t}^{\eta}(1-\eta)\left(h_{t}^{t-2} N_{t}^{t-2}\right)^{\kappa-1} h_{t}^{t-2}}{\left(\left(h_{t}^{t-1} N_{t}^{t-1}\right)^{\kappa}+\left(h_{t}^{t-2} N_{t}^{t-2}\right)^{\kappa}\right)^{\frac{\kappa+\eta-1}{\kappa}}}
$$

where increases in mature worker's wages are also triggered by increases in the capital stock or decreases in the number of mature workers. Now the effects of the young worker's cohort size and the effects of increases in both types of human capital depend on the elasticity of substitution between age groups. Finally, the capital rental rate is equal to:

$$
r_{t}=\frac{\eta\left[\left(\left(h_{t}^{t-1} N_{t}^{t-1}\right)^{\kappa}+\left(h_{t}^{t-2} N_{t}^{t-2}\right)^{\kappa}\right)^{\frac{1}{\kappa}}\right]^{1-\eta}}{K_{t}^{1-\eta}} .
$$

It is clear that this expression increases in the number of young and mature workers as well as their respective human capital endowments and it decreases with the size of the capital stock itself. Consequently, there are diminishing returns to capital.

\section{Analytical Results}

The analytical expression for per capita output in the steady state which can be derived by inserting (4), (6) and (7) into equation (15) is rather cumbersome. Therefore we rely on numerical results regarding the effects of changes in fertility on per capita output and per capita output growth. The related analyses are carried out in section 4. In the following we concentrate on analytical results regarding the sensitivity of relative wage levels of young vs. mature workers. In particular we consider the effect on relative wages of changes in the relative cohort size of young vs. mature workers, of changes in the relative human capital levels of young vs. mature workers and of 
changes in the substitutability between young and mature workers in the production process.

The relative wages of young to mature workers in each time period $t$, can be written as

$$
\frac{w_{t}^{t-1}}{w_{t}^{t-2}}=\frac{\left(h_{t}^{t-1} N_{t}^{t-1}\right)^{\kappa-1} h_{t}^{t-1}}{\left(h_{t}^{t-2} N_{t}^{t-2}\right)^{\kappa-1} h_{t}^{t-2}} .
$$

With the help of this equation the distributional effects of population ageing can be analysed and we state the following rather well known proposition:

Proposition 1 . The relative wages of young workers decrease (increase) with increasing (decreasing) $N_{t}^{t-1} / N_{t}^{t-2}$.

Proof. We take the derivative of young worker's relative wages with respect to the relative size of the young worker's cohort size to obtain

$$
\frac{\partial w_{t}^{t-1} / w_{t}^{t-2}}{\partial N_{t}^{t-1} / N_{t}^{t-2}}=(\kappa-1)\left(\frac{N_{t}^{t-1}}{N_{t}^{t-2}}\right)^{\kappa-2}\left(\frac{h_{t}^{t-1}}{h_{t}^{t-2}}\right)^{\kappa}
$$

which is unambiguously negative, since $\kappa<1$. Therefore proposition 1 holds.

This result tells us that population ageing - as represented by a relative decrease in the number of young to mature workers - is associated with increasing relative wages of young workers. It is due to the fact that young workers become relatively scarce if the population ages.

We next assume, that the relative size of the young worker's labour force stays constant, but allow for changes in the relative human capital levels of young vs. mature workers to state the next proposition:

Proposition 2. The relative wages of young workers increase (decrease) with increasing $h_{t}^{t-1} / h_{t}^{t-2}$ as long as $\kappa$ is larger (smaller) than zero.

Proof. We take the derivative of young worker's relative wages with respect to young worker's relative human capital to get

$$
\begin{aligned}
\frac{\partial w_{t}^{t-1} / w_{t}^{t-2}}{\partial h_{t}^{t-1} / h_{t}^{t-2}} & =\left(\frac{N_{t}^{t-1}}{N_{t}^{t-2}}\right)^{\kappa-1} \kappa\left(\frac{h_{t}^{t-1}}{h_{t}^{t-2}}\right)^{\kappa-1} \\
& <0 \quad \text { if } \quad \kappa<0 \\
& =0 \quad \text { if } \quad \kappa=0 \\
& >0 \quad \text { if } \quad \kappa>0 .
\end{aligned}
$$


Most interestingly, this result indicates that the better education of young workers (as compared to mature workers) does not necessarily lead to a situation where their relative wages are higher. In particular, the effect of an increase in young worker's education has two effects on young worker's wages. First of all, it increases the relative productivity of young workers which unambiguously increases their wages. Secondly, it also increases the overall available efficiency units of young labour which leads to more competition and thus lowers their relative wages. In case that $\kappa>0$, i.e. a high substitutability of young and mature workers in the labour market, the former effect dominates. If however, young and mature workers are difficult to substitute in the labour market, i.e. $\kappa<0$, the latter effect is stronger. Finally, we can analyse the dependence of young worker's relative wages on the substitutability between young and mature workers and state the following:

Proposition 3. The relative wages of young workers decrease (increase) with increasing $\kappa$, if and only if efficiency units of young labour are relatively scarce (abundant).

Proof. To prove proposition 3, we take the derivative of relative wages with respect to $\kappa$ :

$$
\begin{aligned}
\frac{\partial w_{t}^{t-1} / w_{t}^{t-2}}{\partial \kappa} & =\frac{\left(h_{t}^{t-1} N_{t}^{t-1}\right)^{\kappa-1} h_{t}^{t-1}\left(\ln \left(h_{t}^{t-1} N_{t}^{t-1}\right)-\ln \left(h_{t}^{t-2} N_{t}^{t-2}\right)\right)}{\left(h_{t}^{t-2} N_{t}^{t-2}\right)^{\kappa-1} h_{t}^{t-2}} \\
& <0 \text { if } h_{t}^{t-1} N_{t}^{t-1}<h_{t}^{t-2} N_{t}^{t-2} \\
& =0 \text { if } h_{t}^{t-1} N_{t}^{t-1}=h_{t}^{t-2} N_{t}^{t-2} \\
& >0 \text { if } h_{t}^{t-1} N_{t}^{t-1}>h_{t}^{t-2} N_{t}^{t-2}
\end{aligned}
$$

This result states that in case of increasing substitutability and efficiency units of young labour being scarce, relative wages of young workers will decrease. It is intuitively clear because wages of young workers are comparatively high if efficiency units of young labour are scarce. Suppose that in such a situation mature workers learn how to substitute the scarce young workers. This leads to an increase in competition among people who are able to perform the tasks of young workers and it leads to a decrease in competition among people who are able to perform the tasks of mature workers. Consequently, relative wages of young workers will decrease. 


\begin{tabular}{|l|l|l|}
\hline Parameter & Economy 1 & Economy 2 \\
\hline$\alpha$ & 0.9 & 0.9 \\
$\beta$ & 0.8 & 0.8 \\
$\gamma$ & 0.5 & 0.5 \\
$\tau^{f}$ & 0.1 & 0.11 \\
$\tau^{v}$ & 0.1 & 0.1 \\
$\theta$ & 1.5 & 1.5 \\
$\epsilon$ & 0.5 & 0.5 \\
$\eta$ & 0.25 & 0.25 \\
$\kappa$ & 1 & 1 \\
$\delta$ & 0 & 0 \\
\hline \hline Starting Values & Economy 1 & Economy 2 \\
\hline $\mathrm{N}(-3)$ & 1000 & 1000 \\
K(-3) & 1000 & 1000 \\
\hline
\end{tabular}

Table 1: Baseline Parameter Values

\section{Simulations}

In this section we illustrate our analytical results numerically and assess the impacts of demographic change on per capita output levels as well as on per capita output growth rates. The parameter values for a baseline simulation are presented in table 4. We consider two economies which differ only with respect to the fixed costs of children, such that the population size stays constant in economy 1 and it declines in economy 2. Since our model includes 3 generations, the first time period for which all endogenous variables are available is $t=3$. Consequently, the initial values of the capital stock and the population size refer to $t=-3$ and are normalized to 1000 in both economies. There is barely any empirical or theoretical guidance regarding the parameter values we use in our simulation study. If there was such information we used it to assess the specific parameter value, otherwise we chose reasonable ones. The parameters $\alpha$ and $\beta$ were taken such that human capital accumulation exhibits decreasing returns to scale with respect to education. The value of the parameter $\gamma$ ensures that young workers put equal weight on their own consumption and the number as well as the human capital endowment of their children. Fixed costs of each child, $\tau^{f}$ are given as 0.1 in economy 1 and 0.11 in economy 2 such that they amount for roughly $1 / 10$ th of young workers potential income. This ensures that fertility is chosen at the replacement level in economy 1 and below the replacement level in economy 2. Figure 1 plots the corresponding cohort sizes for both economies. Variable costs of children, $\tau^{v}$, are set to 0.1 and refer to each unit of post compulsory education. In our case the accurate interpretation of each unit of education would 
be completed degrees. The parameter $\theta$ which is equal to $1+\rho$, was chosen to guarantee a real interest rate of roughly $80 \%$ between generations or $3 \%$ per year. The intertemporal elasticity of substitution, $1 / \epsilon$, exhibits a value of 2 and the capital share, $\eta$, was set equal to 0.25 , which corresponds to historical values for the United States (see Auerbach and Kotlikoff (1987)). Finally, in the baseline scenario, workers of the two cohorts are perfect substitutes in production, i.e. $\kappa=1$ and learning by doing effects exactly cancel out with human capital depreciation, i.e. $\delta=0$. Simulation is carried out over a period of 8 generations, which corresponds to 160 years. In the following we present 4 alternative scenarios that differ with respect to the human capital accumulation as well as the substitutability of young and mature workers in the labour market.

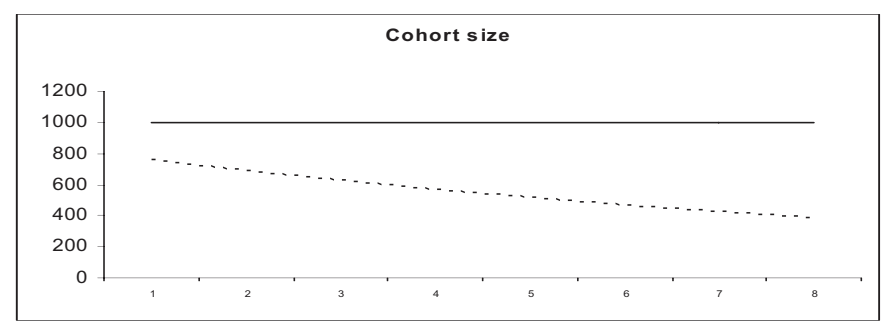

Figure 1: Cohort Sizes of Economy 1 (Solid Line) and Economy 2 (Broken Line)

SCENARIO 1 The results of the baseline simulation for the parameter values given in table 4 are depicted in figure 2. The first picture refers to the growth rate of per capita output, which reveals that in the short-run the economy with a decreasing population size grows faster than the economy with a constant population size. The growth rate is, however, very low in both economies. Consequently, the levels of per capita output do not change substantially over time which can be seen in picture 2. Note that higher human capital investments for both, young and mature workers, lead to higher levels of per capita GDP in the economy with a decreasing population size. Pictures 3 and 4 show the wage levels of young and mature workers. In the economy with a declining population, workers of both cohorts are better educated and relatively scarce as compared to workers in the economy with a constant population size so their wages are higher.

SCENARIO 2 In the second scenario we introduce imperfect substitutability between workers of different age by changing $\kappa$ from 1 to -0.9 . The effect, shown in figure 3 , is that wages in general are far lower in this scenario and therefore savings of 

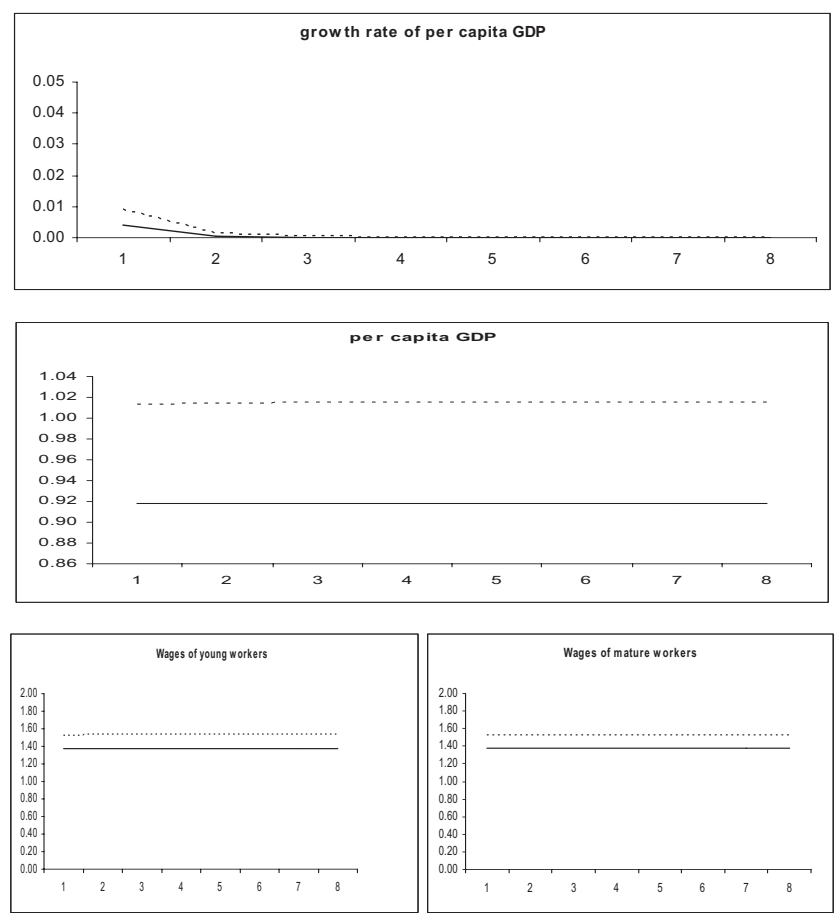

Figure 2: Baseline Simulation of Economy 1 (Solid Line) and Economy 2 (Broken Line)

mature workers are insufficient to maintain the high initial stock of capital. Therefore the capital stock decreases and both economies shrink in terms of per capita output. However, the levels of per capita output are again higher in the economy with a shrinking population since there, workers have higher stocks of physical capital and human capital. Again, the economy with a decreasing population size is able to sustain higher per capita growth rates of output in the short run. There are, however, some remarkable differences to the case of perfect substitutability between workers of different age (Figure 2). In case of imperfect substitutability there occurs a wage gap between young and mature workers in the economy with a declining population. This result can be explained by the fact that there are relatively more mature workers as compared to young workers in the low fertility case but they cannot perfectly substitute these scarce young workers. The introduction of imperfect substitutability thus increases relative wages of the smaller cohort, which ascertains proposition 1 and proposition 3. Moreover, we see that mature workers 

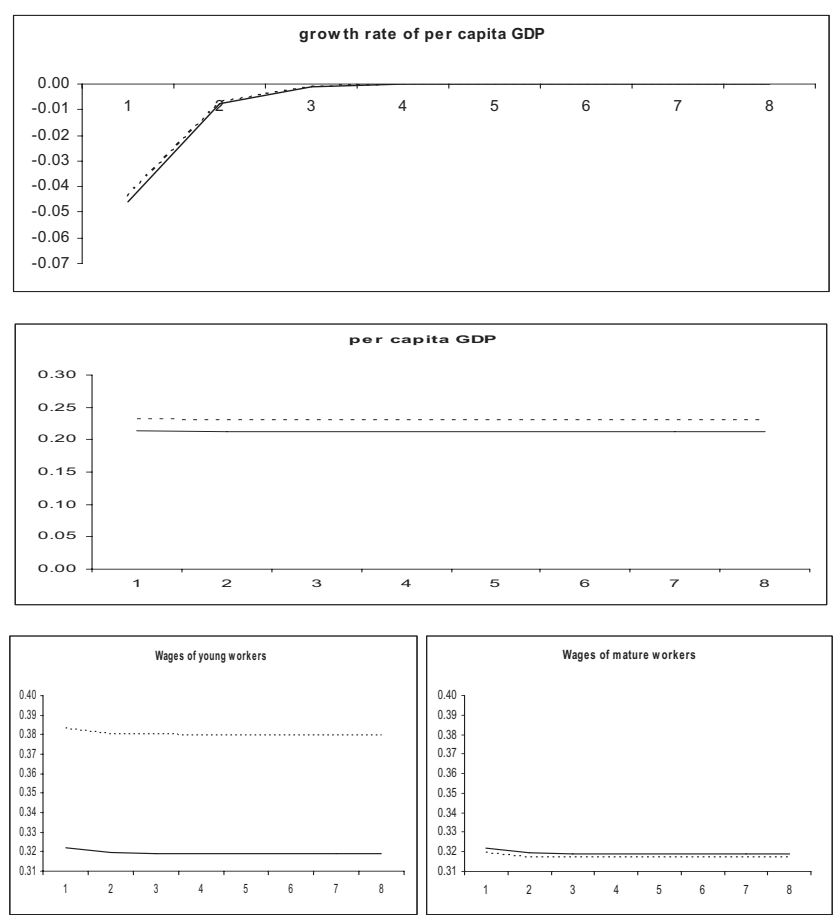

Figure 3: Simulation of Economy 1 (Solid Line) and Economy 2 (Broken Line) for $\kappa=-0.9$

in an economy with decreasing population size have a slightly lower wage as compared to mature workers in an economy with a constant population size. Therefore the overall gains in per capita output resulting from lower fertility are quite unequally distributed: while members of the smaller cohort benefit disproportionately, members of the larger cohort may even have to incur losses.

SCENARIO 3 In scenario 3 we additionally allow learning by doing effects to outweigh human capital depreciation by setting $\delta=0.4$. The results are depicted in figure 4. Similar to the scenarios before, per capita output is higher in the economy where the population shrinks, which is due to the larger individual stocks of physical capital and human capital. Per capita growth of output is negative in both countries but it is slightly higher in the economy with a declining population size. In contrast to the former scenarios, wages of mature workers are substantially lower than wages of young workers, even in the case of a constant population size. Consequently, 

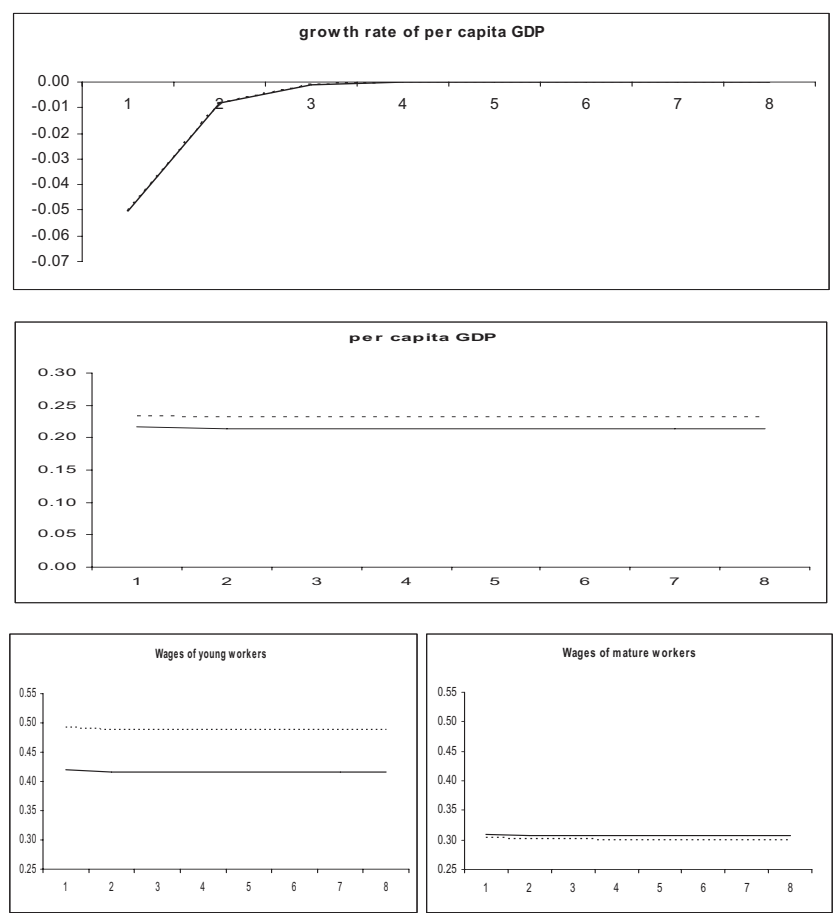

Figure 4: Simulation of Economy 1 (Solid Line) and Economy 2 (Broken Line) for $\kappa=-0.9$ and $\delta=0.4$

these wages are insufficiently low to sustain the initial capital stock. The reason that mature workers wages are that low is that through learning by doing effects, young workers become more productive in the second stage of their life-cycle. Due to the fact that $\kappa$ is smaller than 1 , this implies more competition among mature workers which reduces their wages. Altogether this case confirms proposition 2.

SCENARIO 4 Finally, we allow for human capital depreciation to outweigh learning by doing effects and assume $\delta=-0.4$. In this case mature workers only have $60 \%$ of the human capital they received by education at theit disposal. Consequently, human capital depreciation overcompensates the learning by doing effect such that due to proposition 2 mature worker's wages increase as compared to young worker's wages. As a consequence of the decreased economy-wide human capital level, mature worker's wages are still insufficiently low to sustain the initial capital stock and capital de-accumulation sets in. Therefore per capita output growth turns negative in 

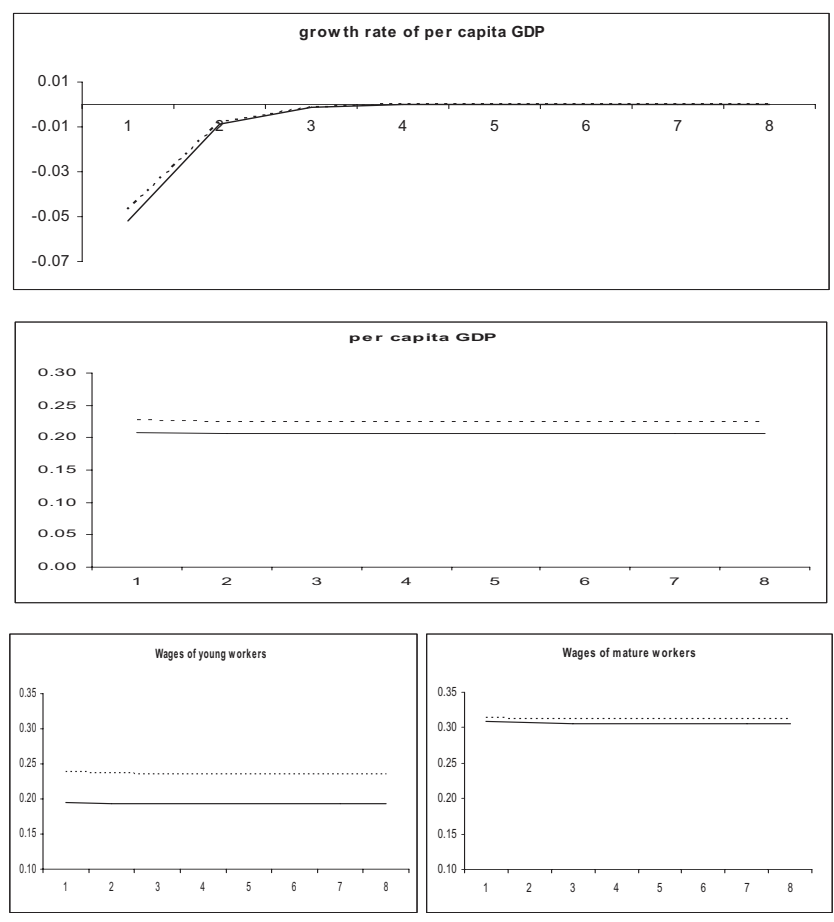

Figure 5: Simulation of Economy 1 (Solid Line) and Economy 2 (Broken Line) for $\kappa=-0.9$ and $\delta=-0.4$

both economies but it is still higher in the country with a decreasing population size.

To summarize, the result that an economy with a decreasing population size grows faster than an economy with a constant population size is robust against the introduction of imperfect substitutability between workers of different age. Per capita GDP is always higher in the economy with low fertility because of the level effect on per capita output coming from higher educational investments into children and therefore higher levels of per capita human capital. Additionally, this result is reinforced by the short-run growth effect that works through higher savings.

Our results regarding the intergenerational wage gap can be summarised by means of figure 6 which plots the relative wages of young vs. mature workers for all four scenarios considered above. We see that there is no wage gap in both economies as long as there is perfect substitutability between young and mature workers. The introduction of imperfect substitutability in the second scenario increases relative 


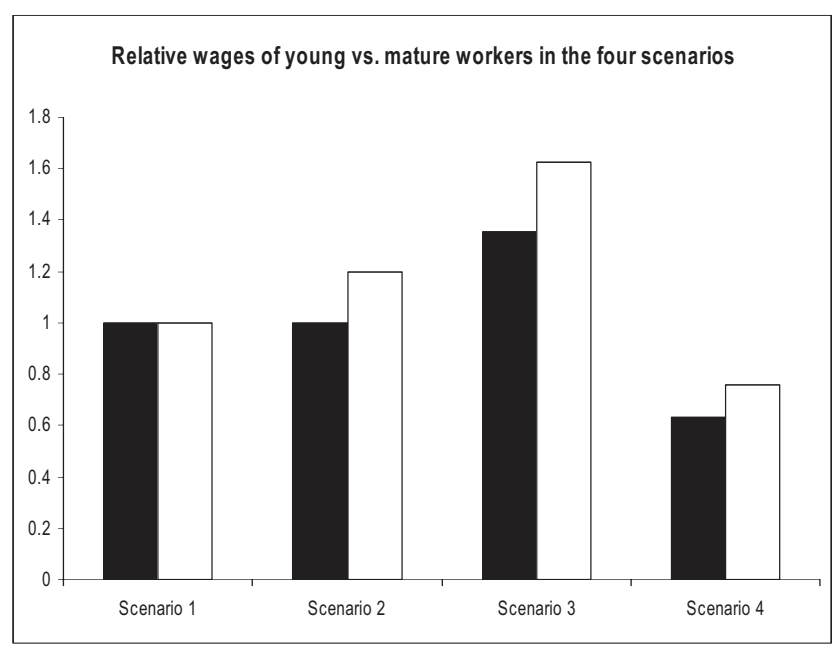

Figure 6: Relative Wages of Young vs. Mature Workers in the Four Scenarios for Economy 1 (Black) and Economy 2 (White)

wages of young workers in the economy where young labour is scarce and thereby ascertains our proposition 3. Increasing the relative human capital endowment of mature workers via strong learning by doing effects decreases their relative wages in scenario 3 which relates to our proposition 2. Note that this result even holds for an economy with constant population size although there it is less pronounced. Furthermore we see that the decrease in the relative human capital endowment of mature workers in scenario 4 works exactly the other way round. Relative wages of young workers decrease because competition is reduced within the group of mature workers. Altogether the implication of proposition 1 is revealed by each scenario: as long as substitution between young and mature workers in the production process is imperfect, decreases in the relative cohort size of young workers increase their relative wages.

In addition to the described effects, the introduction of imperfect substitutability between workers of different cohorts affects the wage gap of mature workers between the two economies: for plausible parameter values, wages of mature workers in an economy with a constant population size can be higher than wages of mature workers in an economy with a decreasing population size. Put differently, lower fertility does not imply higher wages throughout the whole life cycle. Instead, the substitutability of young and mature workers in production will determine in which age group a smaller cohort might gain from lower competition in the labour market. 


\section{Conclusions}

We set up an overlapping generations model with four phases in an individuals lifetime. There are two forces which drive economic development: physical capital accumulation and human capital accumulation. The former is triggered by mature workers who save for their retirement. The latter is performed by young workers who decide upon how much to invest into education of their offspring. Additionally, human capital accumulation can be enhanced via the learning by doing effect. Altogether accumulation of physical capital and human capital lead to a situation where a country with lower fertility rates is able to sustain higher levels of per capita GDP than a country with high fertility. This result is very robust against different parameter specifications and it is also consistent with the literature on exogenous economic growth. Furthermore this result is intuitively clear because a decrease in population growth leads to higher intensities of physical capital and human capital which are, in general, associated with higher per capita output.

Regarding the distributional effects, it can be stated that an increase in the number of workers of a certain cohort decreases the relative wages of members of this cohort. Consequently, population ageing is associated with increasing relative wages of young workers. The impact of increases in the relative human capital of members of a specific cohort are ambiguous and depend on the elasticity of substitution between workers of different age. Higher education of the members of a certain cohort has positive effects on their relative wages as long as substitutability is not too difficult. Otherwise it mainly increases competition within a cohort and therefore decreases the relative wages of their members. Last but not least, increasing difficulties to substitute workers of different age especially decrease wages of members of large cohorts.

Our results suggest that policy-makers should not be concerned about decreases in fertility per se but rather think about implementing accurate incentives for human capital accumulation if it is ensured that young and mature workers can be substituted sufficiently well. These policies, for example subsidies for education or subsidies for on the job training to strengthen learning by doing effects, are able to increase an economies' human capital stock and therefore overall productivity of workers. This in turn increases per capita GDP instantly and fosters per capita output growth in the short-run. The crucial point is that different cohorts are differently affected by these policies. Whether a certain cohort gains or even has to incur losses, crucially depends on the substitutability between workers of different cohorts. Consequently, in order to avoid rising inequality with all its undesired social consequences, policy-makers should carefully investigate whether favourable 
circumstances are met such that both cohorts could gain. If this is not the case, they could try to ensure that sufficient substitutability between workers of different age is guaranteed before they implement the policies mentioned above.

With respect to future research, there is a strong need for empirical investigations on the sign and magnitude of $\kappa$ measuring the degree of substitutability between workers of different cohorts, as this parameter governs the most important distributional effects. In addition, it is required to extend the analysis to large economies or the world economy itself where the technological frontier is determined endogenously. This is on top of our research agenda. 


\section{References}

Aghion, P. and Howitt, P. (1992). A model of growth through creative destruction. Econometrica, Vol. 60(No. 2):323-351.

Auerbach, A. J. and Kotlikoff, L. J. (1987). Dynamic Fiscal Policy. Cambridge University Press.

Becker, G. S. and Tomes, N. (1976). Child endowments and the quantity and quality of children. The Journal of Political Economy, Vol. 84(No. 4):143-162.

Börsch-Suppan, A., Coppola, M., Essig, L., Eymann, A., and Schunk, D. (2008). The German SAVE Study: Design and Results. Universität Mannheim Research Papers.

Diamond, P. A. (1965). National debt in a neoclassical growth model. American Economic Review, Vol. 55(No. 5):1126-1150.

Eurostat (2004). Eurostat yearbook 2004: The statistical guide to Europe. Office for Official Publications of the European Communities.

Galor, O. and Weil, D. (2000). Population, technology, and growth: From malthusian stagnation to the demographic transition and beyond. The American Economic Review, Vol. 90(No. 4):806-828.

Grossman, G. M. and Helpman, E. (1991). Quality ladders in the theory of economic growth. Review of Economic Studies, Vol. 58(No. 1):43-61.

Guest, R. and Shacklock, K. (2005). The impending shift to an older mix of workers: Perspectives from the management and economics literatures. International Journal of Organisational Behaviour, Vol. 10(No. 3):713-728.

Jones, C. I. (1995). R\&D-based models of economic growth. Journal of Political Economy, Vol. 103(No. 4):759-783.

Kortum, S. (1997). Research, patenting and technological change. Econometrica, Vol. 65(No. 6):1389-1419.

Lam, D. (1989). Population growth, age structure, and age-specific productivity. Journal of Population Economics, Vol. 2:189-210.

Lee, R. and Mason, A. (2008). Fertility, human capital, and economic growth over the demographic transition. Mimeo. 
Macunovich, D. J. (2002). Birth Quake: The baby boom and ist aftershocks. Chicago: University of Chicago Press.

Ramsey, F. P. (1928). A mathematical theory of saving. The Economic Journal, Vol. 38(No. 152):543-559.

Romer, P. (1990). Endogenous technological change. Journal of Political Economy, 98(No. 5):71-102.

Segerström, P. S. (1999). Endogenous growth without scale effects. American Economic Review, Vol 88.(No. 5):1290-1310.

Skirbekk, V. (2005). Why not start younger? Implications of the Timing and Duration of Schooling for Fertility, Human Capital, Productivity, and Public Pensions. RR-05-2005, IIASA, Laxenburg.

Solow, R. M. (1956). A contribution to the theory of economic growth. The Quarterly Journal of Economics, Vol. 70(No. 1):65-94.

Strulik, H. and Weisdorf, J. (2008). Population, food, and knowledge: a simple unified growth theory. Journal of Economic Growth, Vol. 13:195-216.

United Nations (2007). World population prospects: The 2006 revision. Url: http://www.un.org/esa/population/publications/wpp2006/english.pdf.

Welch, F. (1979). Effects of cohort size on earnings: The baby boom babies' financial bust. Journal of Political Economy, Vol. 87(No. 5):65-97.

Willis, R. J. (1974). Economic theory of fertility behaviour. In Schultz, T., editor, The Economics of the Family. University of Chicago Press, Chicago, IL. 


\section{VIENNA INSTITUTE OF DEMOGRAPHY}

\section{Working Papers}

Wegner, Christian and Marc Luy, Determinants of General Health and Specific Diseases of Elderly Women and Men: A Longitudinal Analysis for Western and Eastern Germany, VID Working Paper 05/2009.

Wrzaczek, Stefan, Michael Kuhn, Alexia Prskawetz, and Gustav Feichtinger, The Reproductive Value in Distributed Optimal Control Models, VID Working Paper 04/2009.

Wendland, Maike und Isabella Buber, Ein Vergleich der Ergebnisse der ersten Welle des Österreichischen,,Survey of Health, Ageing and Retirement in Europe " (SHARE) und der „Österreichischen Gesundheitsbefragung“ (ATHIS), VID Working Paper 03/2009.

Thomson, Elizabeth, Maria Winkler-Dworak, Martin Spielauer, and Alexia Prskawetz, Union Instability as an Engine of Fertility, VID Working Paper 02/2009.

Grafeneder-Weissteiner, Theresa and Klaus Prettner, Agglomeration and population ageing in a two region model of exogenous growth, VID Working Paper 01/2009.

Skirbekk, Vegard, Anne Goujon, and Eric Kaufmann, Secularism or Catholicism? The Religious Composition of the United States to 2043, VID Working Paper 04/2008.

Ediev, Dalkhat M., Extrapolative Projections of Mortality: Towards a More Consistent Method, VID Working Paper 03/2008.

Schwarz, Franz, Christian Korbel, and Johannes Klotz, Alcohol-Related Mortality among Men in Austria 1981-2002 and the Importance of Qualification and Employment, VID Working Paper 02/2008.

Buber, Isabella and Henriette Engelhardt, The Relation Between Depressive Symptoms and Age Among Older Europeans. Findings from SHARE, VID Working Paper 01/2008.

Aparicio Diaz, Belinda, Thomas Fent, Alexia Prskawetz, and Laura Bernardi, Transition to Parenthood: The role of Social Interaction and Endogenous Networks, VID Working Paper 05/2007.

Ediev, Dalkhat M, On Projecting the Distribution of Private Households by Size, VID Working Paper 04/2007.

The Vienna Institute of Demography Working Paper Series receives only limited review. Views or opinions expressed herein are entirely those of the authors. 